\title{
LINGERING TAXONOMIC CONFUSION IN LABEO \\ (ACTINOPTERYGII: CYPRINIFORMES: CYPRINIDAE): CORRECTING THE RECORDS AND BASIS OF TYPE DESIGNATIONS FOR SEVEN CONGOLESE SPECIES
}

\author{
Maarten VAN STEENBERGE ${ }^{1,2,3^{*}}$, Jos SNOEKS ${ }^{1,2}$, and Emmanuel VREVEN ${ }^{1,2}$ \\ ${ }^{1}$ Ichthyology Group, Vertebrates Section, Royal Museum for Central Africa, Tervuren, Belgium \\ ${ }^{2}$ Laboratory of Biodiversity and Evolutionary Genomics, KU Leuven, Leuven, Belgium \\ ${ }^{3}$ Institute of Zoology, University of Graz, Graz, Austria
}

\begin{abstract}
Van Steenberge M., Snoeks J., Vreven E. 2016. Lingering taxonomic confusion in Labeo (Actinopterygii: Cypriniformes: Cyprinidae): correcting the records and basis of type designations for seven Congolese species. Acta Ichthyol. Piscat. 46 (1): 1-8.
\end{abstract}

Background. The concept of name-bearing specimens is pivotal for nomenclatural stability. Hence, correctly listing the type specimens and designating lecto- and neotypes are crucial elements in taxonomic revisions. While reviewing the Labeo Cuvier, 1816 taxa of the Congo basin, we encountered several differences between the lists of type specimens provided in the various revisions of the genus. The majority of problems were encountered with six nominal species of Labeo that were described by Boulenger in 1898: Labeo barbatus Boulenger, 1898; Labeo falcifer Boulenger, 1898 (later replaced by Labeo falcipinnis Boulenger, 1903); Labeo lineatus Boulenger, 1898; Labeo longipinnis Boulenger, 1898; Labeo macrostoma Boulenger, 1898; and Labeo velifer Boulenger, 1898. For four of these species: L. barbatus, L. lineatus, L. macrostoma, and L. velifer, different specimens appear in the literature as name-bearing types. Also for Labeo lividus Roberts et Stewart, 1975, previously a junior synonym of L. barbatus, and for Labeo altivelis Peters, 1852, a species described from the lower Zambezi but also present in the Congo basin, alternative lists of type specimens were mentioned in the literature.

Material and methods. The correct list of type specimens was compiled based on museum archives and on an examination of the type specimens. The validity of the lectotype designations was checked. When a lectotype designation proved to be ambiguous, the actions of the subsequent revisers were investigated.

Results. We found that the correct lectotypes of L. barbatus, L. falcipinnis, L. lineatus, L. longipinnis, L. macrostoma, and L. velifer are: BMNH 1898.12.28:7, MRAC 17, BMNH 1897.9.30:27, MRAC 113, MRAC 35, and BMNH 1898.12.28:1, respectively. Also for L. lividus and L. altivelis, confusion existed on the type series and a corrected list of type specimens is presented.

Conclusion. Especially in older species descriptions, a detailed list of studied specimens is often lacking. In such cases, providing a correct list of type specimens is often not a trivial task. This study shows that inaccurate lists of type specimens can lead to invalid taxonomic acts, which could have nomenclatural implications. We hope that increased efforts in the dissemination of basic taxonomic information will reduce such errors in the future.

Keywords: taxonomy, Africa, lectotype designation, type specimen, nomenclature

\section{INTRODUCTION}

With over a million nominal species of animals described (Costello et al. 2013), stability in zoological nomenclature is more important than ever. One of the most efficient tools available for achieving this stability is the designation of name-bearing types. Although species names can change as synonymies are proposed and generic rearrangements emerge from novel insights of relatedness, type specimens are fixed, regardless of further studies or changing points of view. Given this importance, it is of no surprise that the necessity of an explicitly listed holotype or syntype series for a valid species description is included in the latest version of the International Code of Zoological Nomenclature (Anonymous 1999: Article 72.3). This was, however, not required for species described prior to 2000. Especially in older descriptions, explicit or even implicit reference to the type specimens is sometimes lacking. This has, in some cases, led to confusion. Before holo- and paratypes were given a separate status, all specimens used for the description of a taxon were viewed as having the same value as syntypes, except when some were explicitly listed as not belonging to the type series or when one

* Correspondence: Dr. Maarten Van Steenberge, Ichtyologie, Dienst Vertebraten, Koninklijk Museum voor Midden Afrika, Leuvensesteenweg 13, 3080 Tervuren, België, phone: +32-2-769-5632, e-mail: (MVS) maarten.vansteenberge@bio.kuleuven.be, (JS) jos.snoeks@africamuseum.be, (EV) emmanuel.vreven@africamuseum.be. 
specimen was explicitly mentioned as being "the type" (Anonymous 1999: Article 73.1.1). Given the advantage of having unique name-bearing specimens, lectotypes are often designated in taxonomic revisions of fishes. The ICZN lists a series of recommendations (Anonymous 1999: 74A-G) for lectotype designations that, when followed, enhance stability. Yet, the only real prerequisite for a lectotype designation to be valid is that the selected specimen is part of the type series (Anonymous 1999: Article 74.2).

Although relatively well studied, the taxonomy of species of the cyprinid genus Labeo Cuvier, 1816 from the Congo basin remains problematic. Congolese Labeo were reviewed by Reid (1985) (for all African species), Tshibwabwa and Teugels (1995) (for species from the Lower Congo), and by Tshibwabwa (1997) (for species from Lower Guinea and the Congo Basin). In his revision of African Labeo, Reid (1985) designated three neotypes and 43 lectotypes. For some of these acts, he was criticised by Thys van den Audenaerde (1987). In subsequent revisions, deviating lists of para-, syn-, or lectotypes were presented (Tshibwabwa and Teugels 1995, Tshibwabwa 1997). Sometimes, a detailed explanation was given that settled the case. This was the case for Labeo greenii Boulenger, 1902 and Labeo degeni Boulenger, 1920. For the former species, Tshibwabwa and Teugels (1995) demonstrated that the original description was based on a single specimen: MRAC 1190, by definition the holotype. This rendered Reid's (1985) lectotype designation, of the same specimen, invalid. For the latter species, Reid (1985) listed BMNH 1919.9.10:192 as the holotype. As Boulenger (1920) mentioned that this species was described based on two syntypes, this act was also considered invalid, and Tshibwabwa and Teugels (1995) designated the other syntype: MRAC 7111, as the lectotype for L. degeni instead.

More problematic were the Labeo species present in the collection made by Lts. Wilverth, Wagenaar, and De Bauw, which was commissioned by the government of the Congo Free State. This fish collection was on display in the colonial exhibit that was part of the Brussels world fair of 1897. Later, it would become part of the collections of the Congo Museum (currently the Royal Museum for Central Africa, RMCA) in Tervuren. When visiting this exhibition in 1897, Boulenger realised that the majority of the fishes on display were new to science and he requested permission to study them. As Boulenger, at the time, was employed at the British Museum of Natural History (BMNH, currently the Natural History Museum, NHM), these specimens were sent to London under the prerequisite that "types" needed to be sent back to Tervuren although "doubles" could be kept in the collections of the NHM (Thys van den Audenaerde 1987). Boulenger (1898) used this collection for the description of six nominal species of Labeo: Labeo barbatus Boulenger, 1898; Labeo falcipinnis Boulenger, 1903, which was originally described as Labeo falcifer Boulenger, 1898, a name which was preoccupied by Labeo falcifer Valenciennes, 1842 (Boulenger 1903); Labeo lineatus Boulenger, 1898; Labeo longipinnis Boulenger, 1898; Labeo macrostoma
Boulenger, 1898; and Labeo velifer Boulenger, 1898. For all of these species, inconsistencies with regard to the listed types were found in the subsequent revisions of the genus (Table 1). These will be discussed below and the correct status and identification of the types will be presented. A note is also included on Labeo lividus Roberts et Stewart, 1976, a species described from the lower Congo rapids, and previously a junior synonym of $L$. barbatus. Additional inconsistencies were further encountered within the type series of Labeo altivelis Peters, 1852, a species described from the lower Zambezi but also present in the upper reaches of the Congo basin.

\section{MATERIALS AND METHODS}

An overview of the type specimens listed in the "checklist of the freshwater fishes of Africa" (CLOFFA, Lévêque and Daget 1984) and in the subsequent revisions on African (Reid 1985) and Congolese Labeo species (Tshibwabwa and Teugels 1995, Tshibwabwa 1997) is provided for L. barbatus, L. falcipinnis, L. lineatus, L. longipinnis, L. macrostoma, and L. velifer, and for L. lividus and L. altivelis (Table 1). For the former six species, the correct list of type specimens was established by analysing the correspondence between Boulenger and the RMCA. These letters are kept in the archives of the Ichthyology lab of the RMCA, where they can be consulted. For each of the revisions (Reid 1985, Tshibwabwa and Teugels 1995, Tshibwabwa 1997), the validity of the lectotype designations was verified. In some cases, two specimens were de facto designated as the lectotype for one and the same species in a single publication. As a lectotype needs to be a unique, unambiguously selected specimen (Anonymous 1999: Article 74.1), these designations are conflicting nomenclatural acts. Therefore, the actions of subsequent authors had to be taken into account. Type specimens were examined, museum archives and catalogues were consulted and labels were checked. Several paralectotypes were re-identified. Institutional abbreviations for collections follow Eschmeyer and Fricke (2015). This implies that for the collections, the RMCA and the NHM will be referred to as MRAC and $\mathrm{BMNH}$, respectively.

\section{RESULTS}

Labeo specimens sent to G.A. Boulenger in London. For the six species of Labeo-described in Boulenger's (1898) publication: L. barbatus, L. falcipinnis (originally described as $L$. falcifer), L. lineatus, L. longipinnis, L. macrostoma, and $L$. velifer-no collection numbers of the specimens used for the original descriptions were provided. Yet, for species described before 2000, any evidence, published or unpublished, may be taken into account to determine what specimens constitute the type series (Anonymous 1999: Article 72.4.1.1). In this case, a list of 147 specimens that were shipped from the Congo Museum to the BMNH was included in the correspondence between E. Coart, secretary and future director of the Congo Museum and G.A. Boulenger (6 June 1898). More importantly, Boulenger added a detailed list 


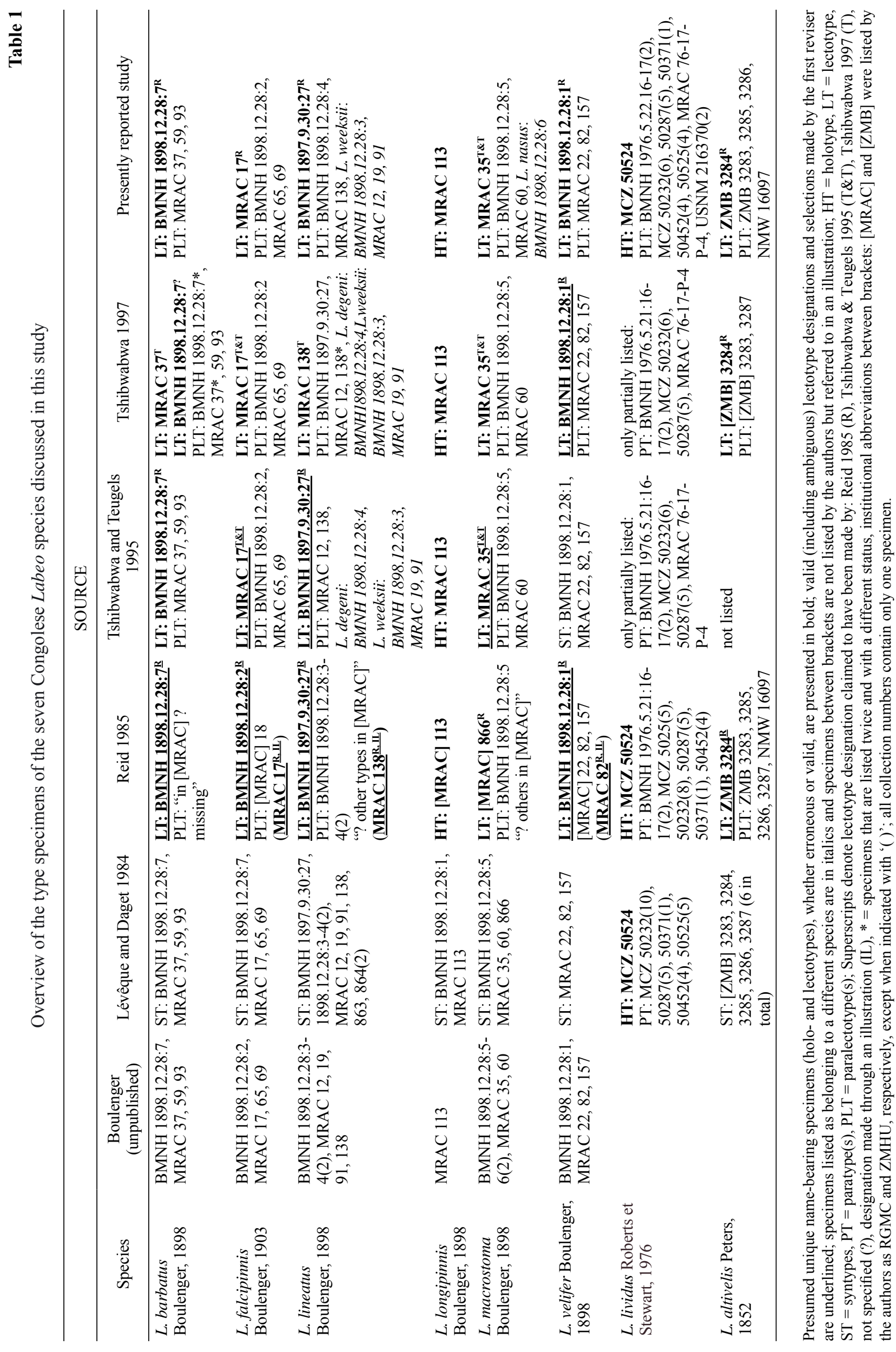


of identifications to the collections when these were sent back. Here, 23 specimens were mentioned that served for the description of these six Labeo species. Hence, these specimens should all be considered types. As this list was preserved, the collection numbers of these specimens could be traced.

As many specimens from the original collection of the Congo exhibition stayed in London and therefore were no longer part of the RMCA collection, by the end of the 1940s, a new numbering system was put in place. Yet, the link with the original collection numbers was kept as the new collection numbers were added to the original registers. Hence, we were able to identify the Labeo types in the RMCA belonging to this collection. In Boulenger's list of identifications, the original collection numbers of seven specimens of $L$. barbatus, $L$. falcipinnis, L. lineatus, $L$. macrostoma, and $L$. velifer were put between brackets. These specimens apparently stayed in the NHM. When consulting the registers of the NHM online, we noticed that these specimens were registered under the collection numbers BMNH 1898.12.28:1 through 7 (Table 1).

For each species, one collection number was underlined in Boulenger's list of identifications. This was also the only number that was originally listed in the registers of the RMCA as the 'type', together with the abbreviation SN (spécimen nominal). We studied the specimens corresponding to the underlined collection numbers and these proved to be the illustrated specimens presented in the original species descriptions (Boulenger 1898). These specimens are: MRAC 37 for L. barbatus, MRAC 17 for L. falcifer Boulenger, 1898 (later replaced by L. falcipinnis Boulenger, 1903), MRAC 138 for L. lineatus, MRAC 113 for L. longipinnis, MRAC 35 for L. macrostoma, and MRAC 82 for $L$. velifer. However, except for providing illustrations of them, Boulenger (1898) did not treat these specimens differently in the original descriptions. Hence, except for MRAC 113, the sole type specimen and therefore the holotype of $L$. longipinnis, all 23 Labeo specimens sent to Boulenger had, at the time, equal status as syntypes.

Confusion on the type series of the Labeo species from the Congo exhibition. In spite of the detailed list of identifications provided by Boulenger, different authors provided different lists of type specimens (Table 1). Partially, this could be explained by the fact that the information present in Boulenger's correspondence has never been published. Yet, based on this correspondence, we obtained the complete list of specimens sent from the Congo exhibition to the NHM, which contained the type specimens of the six species (Table 1). Here, we clarify some of the confusion concerning the type series of L. barbatus, L. falcipinnis, L. lineatus, and L. macrostoma.

In the description of L. barbatus, Boulenger (1898) stated that he used specimens from Boma and Matadi. Therefore, specimen MRAC 93, from Manyanga, could, at first sight, not be part of the type series. However, Boulenger (1898) mentioned that he had, next to a large specimen (MRAC 37, from Matadi), several juvenile specimens from Matadi at his disposal. Boulenger (1909) only mentioned the presence of one type in the
NHM (corresponding to BMNH 1898.12.28:7, from Boma). Hence, all Matadi specimens must be in the collections of the RMCA. As no other L. barbatus were present in the collections at the time, these juveniles must correspond with MRAC 59 (from Matadi) and MRAC 93 (from Manyanga). Most probably, Boulenger (1898) made a mistake in referring to the Manyanga specimen as also originating from Matadi. Reid (1985) mentioned that besides BMNH 1898.12.28:7, all other type specimens of L. barbatus were probably missing. They were, however, present in the RMCA collections.

As L. falcipinnis was published as a replacement name of L. falcifer Boulenger, 1898, which was preoccupied by L. falcifer Valenciennes, 1842 (currently Lobocheilos falcifer, from Southeast Asia), both species have the same name-bearing types (Anonymous 1999: Article 72:7). For L. falcipinnis, Reid (1985) erroneously listed MRAC 18 (using the old abbreviation RGMC 18) as the sole paralectotype. Although this specimen was also part of the original collection of the Congo exhibition, it is not a Labeo, but a Synodontis Cuvier, 1816 catfish. Boulenger (1899) used this specimen for the description of Synodontis acanthomias Boulenger, 1899, for which it is the lectotype (designated by Poll 1971).

The specimen that Reid (1985) listed as the lectotype of L. lineatus: BMNH 1897.9.30:27 (Table 1), was not one of the six types listed in Boulenger's correspondence. Yet, in the description of L. lineatus, Boulenger (1898) mentioned that a specimen was "also" collected by Bentley at Stanley Falls. This implies that, next to the specimens present in the collection of the Congo exhibition, which were collected by Wilverth, Wagenaar, and De Bauw, an additional specimen was available. Hence, BMNH 1897.9.30:27 represents the seventh type specimen of L. lineatus. This specimen was originally identified as Labeo brachypoma Günther, 1868. Lévêque and Daget (1984) listed additional types of L. lineatus and included MRAC 863 and MRAC 864 (2) in the list of syntypes. Yet, Tshibwabwa and Teugels (1995) showed this to be wrong as Delhez - a naturalist and artist who worked as a collector in service of the government of the Congo Free State - collected these specimens between the 11 and the 18 of February 1899. Hence, Boulenger could not have used them for the description of L. lineatus, which was published in December 1898.

Although the BMNH registers and the correspondence between Boulenger and the RMCA showed that BMNH 1898.12.28:6 was a syntype of L. macrostoma, this specimen was not listed as such in any of the revisions (Reid 1985, Tshibwabwa and Teugels 1995, Tshibwabwa 1997) nor in the "Check-list of the fresh water fishes of Africa" (Lévêque and Daget 1984) (Table 1). This specimen subsequently served, together with MRAC 867 , as a syntype for the description of Labeo nasus Boulenger, 1899. Reid (1985) later designated MRAC 867 as the lectotype of this species. As BMNH 1898.12.28:6 was also a type specimen of $L$. nasus, it was probably overlooked by subsequent authors as a member of the type series of L. macrostoma. 
Conflicting and erroneous lectotype designations. In his revision of African Labeo, Reid (1985) designated lectotypes for all of the six species present in the collection of the Congo exhibition except for L. longipinnis. The following numbers were provided (Reid 1985): BMNH 1898.12.28:7 for L. barbatus; BMNH 1898.12.28:2 for L. falcipinnis; BMNH 1897.9.30:27 for L. lineatus; MRAC 866 for L. macrostoma; and BMNH 1898.12.28:1 for L. velifer (Table 1). For this, he was criticised by Thys van den Audenaerde (1987), who referred to a convention between Boulenger and the RMCA that only doubles were to be kept in the collections of the $\mathrm{BMNH}$ and that unique name-bearing types were registered in the RMCA. Boulenger indeed acted according to this convention by returning the illustrated specimens to the RMCA. Only this specimen was listed as "type" in the register of the RMCA. For the other specimens, a note stating that they were syntypes was added later. Thys van den Audenaerde (1987) argued that Boulenger (1909) also followed this convention in his "Catalogue of the fresh-water Fishes of Africa in the British Museum". Here, all syntypes that remained in the NHM were listed as being "one of the types". Those that were returned to the RMCA were listed as "types" and the illustrated specimen was referred to as the "type". Boulenger (1909) did, however, use the word "types" in his catalogue to refer to the type specimens of species for which the complete type series was housed in the NHM (e.g., for Labeo brachypoma Günther, 1868 and for Labeo walkeri Günther, 1903). Although this could suggest that Boulenger already had a notion of holo- and paratypes in mind, this distinction was not yet clearly made at the end of the 19th century. Hence, all type specimens of L. barbatus, L. falcipinnis, L. lineatus, L. macrostoma, and $L$. velifer had equal status as syntypes. The convention referred to by Thys van den Audenaerde (1987) does not challenge the validity of the lectotype designations made by Reid (1985). Hence, the fact that for some of these species, other specimens than those put forward by Boulenger (1898) were designated as lectotypes seems irrelevant. Yet, there is more to the story.

For all six Labeo species described by Boulenger (1898), Reid (1985) provided the same illustrations as Boulenger (1898). For L. falcipinnis, L. lineatus, and $L$. velifer, but not for $L$. barbatus and $L$. macrostoma, Reid (1985) referred to these figures as representing the species' lectotype. A lectotype designation by means of an illustration is to be treated as a designation of the specimen illustrated (Anonymous 1999: Article 74.4). Hence, Reid (1985) implicitly designated MRAC 17, MRAC 138, and MRAC 82 as the lectotypes of $L$. falcipinnis, L. lineatus, and $L$. velifer, respectively. This implies that he provided two separate lectotype designations for these three species, one by means of an illustrated specimen (MRAC 17, MRAC 138, and MRAC 82 for L. falcipinnis, L. lineatus, and $L$. velifer, respectively) and one by means of a collection number (BMNH 1898.12.28:2, BMNH 1897.9.30:27, and BMNH 1898.12.28:1 for L. falcipinnis, L. lineatus, and L. velifer, respectively). As there is no page priority in nomenclatural acts, none of these double designations has priority over the other. Hence, following the principle of the first reviser (Anonymous 1999: Article 24.2), the first author that selects one of these acts needs to be followed.

Also for L. barbatus, the illustrated specimen does not correspond to the number of the lectotype given by Reid (1985). Yet, no reference is given about the type status of the illustrated specimen. Therefore, the designation of BMNH 1898.12.28:7 as the lectotype of L. barbatus is valid, notwithstanding institutional conventions or the fact that recommendations 74 B, E, and F (Anonymous 1999) were ignored. This implies that the subsequent lectotype designations for this species done by Tshibwabwa (1997), which were ambiguous (Table 1), can be ignored. Finally, Tshibwabwa and Teugels (1995) demonstrated that the specimen Reid (1895) designated as the lectotype of L. macrostoma (MRAC 866) was not part of the original type series, as it was collected after the species was described. Further, it was not listed in Boulenger's correspondence either. Therefore, Tshibwabwa and Teugels (1995) designated MRAC 35 as the lectotype of L. macrostoma instead.

As Reid's (1985) lectotype designations for L. falcipinnis, L. lineatus, and L. velifer were ambiguous, the actions of further reviewers needed to be taken into account. Remarkably, Tshibwabwa and Teugels (1995) and Tshibwabwa (1997) differed largely in accepting the different lectotype designations made by Reid (1985), without providing an explanation for this. In several cases, they ignored Reid's (1985) actions and designated lectotypes themselves. Such a 'designation' should, however, be interpreted as a selection by the first reviser if the specimen is one of Reid's (1985) ambiguously defined 'lectotypes'. For L. falcipinnis, Tshibwabwa and Teugels (1995) claimed to designate MRAC 17, the illustrated specimen from the original description (Boulenger 1898), as the lectotype, hence implicitly rejecting Reid's designation of BMNH 1898.12.28:2 as the lectotype. For L. lineatus, they accepted BMNH 1897.9.30:27 as the lectotype, as designated by Reid (1985), also without further comments. For L. velifer, however, Tshibwabwa and Teugels (1995) ignored Reid's lectotype designations and listed all specimens as syntypes. Tshibwabwa (1997) followed Tshibwabwa and Teugels (1995) for L. falcipinnis, in listing MRAC 17 as the lectotype. For L. lineatus, he disagreed with Tshibwabwa and Teugels (1995) and claimed to designate MRAC 138 as the lectotype instead. For this, he referred to the convention between G.A. Boulenger and the RMCA, which was discussed above. Tshibwabwa (1997) did, however, list MRAC 138 both as the lectotype and as a paralectotype of L. lineatus. For L. velifer, Tshibwabwa (1997) referred to BMNH 1898.12.28:1 as the lectotype as designated by Reid (1985) (Table 1).

Given the ambiguity of three of Reid's (1985) lectotype designations (see above), Tshibwabwa and Teugels (1995) are to be considered the first revisers that selected MRAC 17 as the lectotype of L. falcipinnis and BMNH 1897.9.30:27 as the lectotype of L. lineatus. Tshibwabwa (1997) acted 
as the first reviser in selecting BMNH 1898.12.28:1 as the lectotype of $L$. velifer. Reid (1985) remains, however, the author of these lectotype designations (see the example at Anonymous 1999: Article 24.2).

The composite nature of the type series of L. macrostoma and $\boldsymbol{L}$. lineatus. For two of the six species in the collection of the Congo exhibition, the type series proved to be polyspecific. The first case concerns the type series of $L$. macrostoma, for which we already mentioned above that BMNH.12.28:6 is a paralectotype of both L. macrostoma and L. nasus.

Tshibwabwa and Teugels (1995) showed that the type series of $L$. lineatus is polyspecific as well. They transferred BMNH 1898.12.28:4 to $L$. degeni and BMNH 1898.12.28:3, MRAC 19 and 91 to Labeo weeksii Boulenger, 1909. We verified these identifications and confirmed the re-identifications except for BMNH 1898.12.28:4, which belongs to L. lineatus and not to L. degeni. In addition, MRAC 12 also proved to be a $L$. weeksii. Therefore, of the six paralectotypes of L. lineatus: only two (BMNH 1898.12.28:4 and MRAC 138) are conspecific with the lectotype (Table 1). Also for L. barbatus, it was suggested that the type series is polyspecific as one paralectotype has been re-identified as L. lividus. This will be discussed in the following section. The revalidation of $L$. lividus and its affinity with L. barbatus. In a study on the ichthyofauna of the rapids of the lower Congo River (Roberts and Stewart 1976), L. lividus was described, a species claimed to be very similar to $L$. barbatus. Although this was not explicitly mentioned in the description of the species, Roberts re-identified MRAC 93 (at that time a syntype of L. barbatus) as L. lividus. Given their similarity, Reid (1985) synonymised L. lividus with $L$. barbatus, albeit with hesitation. This synonymy was further confirmed by Tshibwabwa and Teugels (1995) and by Tshibwabwa (1997).

In a DNA barcoding study, however, Lowenstein et al. (2011) found molecular support for a separate specific status of L. lividus. They revalidated L. lividus and confirmed the distinguishing characters listed by Roberts and Stewart (1976) that differentiate the two species: shorter, paler barbels and larger, more heavily keratinised lip papillae in L. lividus than in L. barbatus. Roberts and Stewart (1976) further mentioned that in L. barbatus, both barbels are of almost equal length whereas in L. lividus the anterior barbels are shorter than the posterior. We examined specimen MRAC 93 and compared it with a paratype of L. lividus housed in the RMCA (MRAC 76.17.P.4) and with the description of the species. Although this specimen has the characteristic large keratinised papillae of L. lividus on its lower lips, its anterior and posterior barbels are of almost equal length, as in L. barbatus. A morphometric study including type specimens of both species, however, confirmed the status of MRAC 93 as L. barbatus. It should be noted that the morphological differences between $L$. barbatus and L. lividus need to be examined in more detail, which will be part of a forthcoming study. The type series of L. lividus, containing 26 specimens was originally housed in the MCZ. Afterwards, some of the paratypes have been transferred to three additional museums, i.e., the MCZ, NHM, and RMCA (Table 1).

Note on the type series of $L$. altivelis. Some problems were also encountered with the type series of L. altivelis Peters, 1852. In the original description, Peters (1852) mentioned that the specimens originated from Tete, without mentioning how many were used for the description. Yet, as Peters (1852) listed variation in scale counts, there must be more than one type specimen. Reid (1985) designated a lectotype, both by referring to an illustration (taken from Peters 1868) and by listing collection number ZMB 3284. After examination of the type series, we found that the illustrated specimen indeed corresponded to ZMB 3284. For the paralectotypes, Reid (1985) listed: ZMB 3283, 3285, 3286, 3287, and NMW 16097 whereas Tshibwabwa (1997) only mentioned ZMB 3283 and 3287 (both used the abbreviation for the Berlin museum in use at the time: ZMHU). Both authors erroneously referred to five and three type specimens (lecto- and paralectotypes) housed in the Berlin museum respectively, hence ignoring that two specimens were catalogued under ZMB 3287. These two specimens, however, did not originate from Tete, but from Quellimane (on the Rio de Bons Sinais), a locality mentioned in a redescription of the species (Peters 1868), together with the Licuare River (a tributary of the Rio de Bons Sinais basin, near Quellimane) and Sena (on the Zambezi), but not in the original description. Therefore, these specimens (ZMB 3287) are not types. Specimens ZMB 3283, 3285, and 3286 are all from the type locality and were caught at the same time by the same collector. Moreover, specimen ZMB 3286 was even kept in the same jar as the lectotype. Hence, there is no reason not to consider these specimens as paralectotypes. As for the specimen in the Vienna museum, NMW 16097, it could only be confirmed that this specimen originates from Mozambique and came in the possession of the Vienna museum in 1854. This specimen was acquired through an exchange with Peters, so it cannot be excluded that this is also a type. Moreover, it was exchanged for 24 specimens, which indicates its high value (Wellendorf H. 2014, personal communication). Therefore, until further clarification, NMW 16097 ought to be considered the fourth paralectotype of L. altivelis.

\section{DISCUSSION}

This study exemplifies that correctly listing the types of a given species is often not a trivial task. Indeed, it has potentially profound consequences as nomenclatural stability depends heavily on name-bearing types. Fortunately, the taxonomic issues presented here did not have any nomenclatural consequences. Yet, given the composite nature of the type series of L. lineatus and L. macrostoma, nomenclatural confusion could have arisen easily. For L. lineatus, more than half of the type specimens are L. weeksii. Luckily, the different authors referred to the same biological species when they discussed L. lineatus. Indeed, the true (BMNH 1897.9.30:27) and the 'erroneous' lectotype (MRAC 138) do belong to the same species. Yet, the importance of a careful designation 
of a lectotype is perhaps best illustrated by the cases of L. macrostoma and L. nasus. Until Reid's (1985) revision, specimen BMNH 1898.12.28:6 was a syntype, and therefore a name-bearing specimen of both nominal species. Hence, if a different choice of lectotypes had been made, these species would have become synonymies even though two biological species do exist. Given the important nomenclatorial consequences of lectotype designations, the ICZN specifies that they need to be done individually (Anonymous 1999: Article 74.3) and should be done as part of a revisionary work (Anonymous 1999: Recommendation 74G). The current study should therefore be viewed as part of an ongoing endeavour to revise the Labeo of the Congo basin (Van Steenberge et al. 2014).

Especially in older species descriptions, it was not common practice to list the number of specimens used, let alone to mention their collection numbers. This problem is recognised by the ICZN as the code explicitly allows the usage of all kinds of evidence to determine what specimens constitute the type series (Anonymous 1999: Article 72.4.1.1). Hence, correctly listing the types may require studying the original literature, the museum registers and databases, investigating specimens and museum labels and, potentially, speculating on the intentions of the author or the reviewer.

Yet, incomplete knowledge of a species' type series could unintentionally lead to violations of the rules of the international code of zoological nomenclature and to nomenclatural instability. In this regard, we can only applaud initiatives such as the Catalogue of Fishes (Eschmeyer and Fricke 2015), which disseminates crucial basic taxonomic information, including lists of type specimens. Moreover, the increasing effort put in the digitalisation of natural history collections (Baird 2010), e.g., in FishBase (Froese and Pauly 2016), will hopefully reduce the number of taxonomic inconsistencies in the future.

\section{ACKNOWLEDGMENTS}

We thank Laura Gajdzik (ULg, Belgium), Alex Chilala (DF, Zambia), Sarah Tilkin (KU Leuven), and Miguël Parrent (RMCA) for their help in the study of African Labeo, and James Maclaine (NHM), Helmut Wellendorf (NMW), Peter Bartsch and Christa Lamour (ZMB) for their hospitality during study visits. Study visits of EV to the ZMB were supported by Synthesis grants: DE-TAF-1802, April 2012 and DE-TAF-3590, April 2014. Results were presented at the 5th PAFFA conference in Bujumbura (Burundi) with support of the All Cypriniformes Species Inventory (ACSI-2) project.

\section{REFERENCES}

Anonymous 1999. International Code of Zoological Nomenclature. International Commission on Zoological Nomenclature, The Natural History Museum, London.

Baird R. 2010. Leveraging the fullest potential of scientific collections through digitization. Biodiversity Informatics 7 (2): 130-136.

DOI: $10.17161 /$ bi.v7i2.3987
Boulenger G.A. 1898. Poissons nouveaux du Congo. Deuxième Partie. Elopes, Characins, Cyprins. In: Boulenger G.A. Matériaux pour la faune du Congo. Annales du Musée du Congo, Serie I - Zoologie 1 (2): 21-38.

Boulenger G.A. 1899. Poissons nouveaux du Congo. Cinquième Partie. Cyprins, Silures, Cyprinodontes, Acanthoptérygiens. In: Boulenger G.A. Matériaux pour la faune du Congo. Annales du Musée du Congo, Serie I - Zoologie 1 (5): 97-128.

Boulenger G.A. 1903. XXXIV.-List of the African species of the cyprinid genus Labeo, with a key to their identification. Annals and Magazine of Natural History, Series 712 (69): 355-362. DOI: $10.1080 / 00222930308678867$

Boulenger G.A. 1909. Catalogue of the fresh-water fishes of Africa in the British Museum (Natural History). British Museum (Natural History), London. DOI: $10.5962 /$ bhl.title.8869

Boulenger G.A. 1920. Poissons recueillis au Congo Belge par l'expédition du $\mathrm{D}^{\mathrm{r}} \mathrm{C}$. Christy. (Matériaux pour la faune du Congo). Annales du Musée du Congo Belge, Zoologie - Série I 2 (4): 1-38.

Costello M.J., May R.M., Stork N.E. 2013. Can we name earth's species before they go extinct? Science 339 (6119): 413-416.

DOI: $10.1126 /$ science. 1230318

Eschmeyer W.N., Fricke R. (eds.) 2015. Catalog of fishes: Genera, species, references. California Academy of Sciences, San Francisco, USA. http://research.calacademy. org/research/inchthyology/catalog/fishcatmain.asp [Accessed on 11 January 2015.]

Froese R., Pauly D. (eds.) 2016. FishBase. [Version 01/2016] www.fishbase.org

Lévêque C., Daget J. 1984. Cyprinidae. Pp. 217-342. In: Daget J., Gosse J., Thys van den Audenaerde D.F.E. (eds.) Check-list of the freshwater fishes of Africa (CLOFFA). Vol. 1. ORSTOM, Paris and MRAC, Tervuren.

Lowenstein J.H., Osmundson T.W., Becker S., Hanner R., Stiassny M.L.J. 2011. Incorporating DNA barcodes into a multi-year inventory of the fishes of the hyperdiverse lower Congo River, with a multigene performance assessment of the genus Labeo as a case study. Mitochondrial DNA 22 (Suppl. 1): 52-70. DOI: $10.3109 / 19401736.2010 .537748$

Peters [W.] 1852. [...] diagnosen von neuen Flussfischen aus Mossambique. Bericht über die zur Bekanntmachung geeigneten Verhandlungen der Königlich Preussischen Akademie der Wissenschaften zu Berlin 1852: 681-685.

Peters W.C.H. 1868. Naturwissenschaftliche Reise nach Mossambique auf Befehl Seiner Majestät des Königs Friedrich Wilhelm IV. in den Jahren 1842 bis 1848 ausgeführt. Zoologie. IV. Flussfische. Georg Reimer, Berlin.

Poll M. 1971. Révision des Synodontis africains (Famille Mochocidae). Musée Royal de l'Afrique Centrale Tervuren Belgique, Annales, Serie in- $8^{\circ}-$ Sciences Zoologiques No. 191: 1-497. 
Reid G.McG. 1985. A revision of the African species of Labeo (Pisces: Cyprinidae) and a re-definition of the genus. Theses zoologicae 6: 1-322.

Roberts T.D., Stewart D.J. 1976. An ecological and systematic survey of fishes in the rapids of the lower Zaire or Congo River. Bulletin of the Museum of Comparative Zoology 147 (6): 329-317.

Thys van den Audenaerde D.F.E. 1987. Review: Reid, G.McG., 1985, A revision of the African species of Labeo (Pisces, Cyprinidae). Revue de Zoologie Africaine 100: 487-492.

Tshibwabwa S.M. 1997. Systématic des espèces Africaines du genre Labeo (Teleostei, Cyprinidae) dans les regions ichthyogéographiques de BasseGuinée et du Congo. Presses Universitaires de Namur.
Tshibwabwa S.M., Teugels G.G. 1995. Contribution to the systematic revision of the African cyprinid genus Labeo: species from the lower Zaire River system. Journal of Natural History 29 (6): 1543-1579. DOI: $10.1080 / 00222939500770661$

Van Steenberge M., Gajdzik L., Chilala A., Snoeks J., Vreven E. 2014. Labeo rosae (Cypriniformes: Cyprinidae) in the Congo basin: a relict distribution or a historical introduction? Journal of Fish Biology 85 (5): 1733-1738.

DOI: $10.1111 / \mathrm{jfb} .12491$

Received: 15 September 2015

Accepted: 2 December 2015

Published electronically: 31 March 2016 